\title{
Surgical extrusion of a maxillary premolar after orthodontic extrusion: a retrospective study
}

\author{
Yong-Hoon Choi ${ }^{1}$, Hyo-Jung Lee ${ }^{2}$ \\ Departments of ${ }^{1}$ Conservative Dentistry and ${ }^{2}$ Periodontology, Section of Dentistry, Seoul National University Bundang Hospital, \\ Seongnam, Korea
}

\begin{abstract}
J Korean Assoc Oral Maxillofac Surg 2019;45:254-259)
Objectives: Crown-root fracture and cervical caries in maxillary premolars constitute a challenge in cases of subgingival placement of restoration margins. Surgical extrusion has been practiced successfully in permanent anterior teeth. The aim of the present retrospective study was to assess the clinical outcome of surgical extrusion after orthodontic extrusion in maxillary premolars.

Materials and Methods: Twenty-one single, tapered root maxillary premolars with subgingival crown-root fracture or caries were included. Presurgical orthodontic extrusion was performed on all teeth to prevent root resorption. Extent of extrusion and rotation was determined based on crown/root ratio. The postoperative splinting period was 7 to 14 days. Clinical and radiographic examination was performed at an interval of 1,2, and 3 months. Results: After the mean follow-up of $41.9 \pm 15.2$ months, failure was observed as increased mobility in 3 of 21 cases. No significant difference was observed in the outcome of surgical extrusion based on tooth type, age, sex, $180^{\circ}$ rotation, or time for extraction. Furthermore, marginal bone loss was not observed.
\end{abstract}

Conclusion: Surgical extrusion of maxillary premolars can be a possible therapeutic option in cases of subgingival crown-root fracture.

Key words: Surgical extrusion, Maxillary premolar, Surgical crown lengthening

[paper submitted 2019. 1. 8 / revised 2019. 3. 15 / accepted 2019. 3. 18]

\section{Introduction}

The incidence of crown-root fracture in permanent dentition is approximately $5 \%{ }^{1}$. Increasing prevalence of subgingival root caries has been reported in older individuals ${ }^{2}$. Maintenance of cervical tooth structure to create a ferrule effect is crucial to optimize the biomechanical properties of the restored tooth ${ }^{3}$. In cases where clinicians are considering preservation of the natural tooth, treatment options often include surgical crown lengthening, orthodontic extrusion, and surgical extrusion with or without rotation ${ }^{4}$.

\section{Hyo-Jung Lee}

Department of Periodontology, Section of Dentistry, Seoul National University Bundang Hospital, 82 Gumi-ro 173beon-gil, Bundang-gu, Seongnam 13620, Korea

TEL: +82-31-787-7547 FAX: +82-31-787-4068

E-mail:65592@snubh.org

ORCID: https://orcid.org/0000-0002-0439-7389

(c) This is an open-access article distributed under the terms of the Creative Commons Attribution Non-Commercial License (http://creativecommons.org/ licenses/by-nc/4.0/), which permits unrestricted non-commercial use, distribution, and reproduction in any medium, provided the original work is properly cited.

Copyright (C) 2019 The Korean Association of Oral and Maxillofacial Surgeons. All rights reserved.
Surgical crown lengthening reestablishes the dentinoenamel junction by removing the soft tissue and supporting alveolar bone, if indicated, to achieve a supragingival margin ${ }^{5}$. This procedure increases the crown-root ratio, which may result in increased mobility of the tooth ${ }^{6}$. In addition, lack of supporting alveolar bone could pose a challenge during future restorations with dental implants ${ }^{7}$. Orthodontic extrusion is performed to relocate all margins of the traumatized tooth to a more coronal position through application of an extrusive force ${ }^{8}$. This procedure is preferred over surgical crown lengthening due to the ability to obtain a better crownroot ratio. However, the procedure is time consuming and may necessitate an additional surgical procedure ${ }^{9}$. Neither of the above-mentioned procedures can be performed to achieve appropriate crown-root ratios in cases of short residual root lengths.

Surgical extrusion comprises luxation of the root with instruments (forceps, periotomes, fine elevators, etc.), positioning the margin at a juxtagingival level with or without rotation, and securing the final position using sutures or a resin wire splint $t^{4,10}$. The known advantages of surgical extrusion 
are minor to no destruction of periodontal tissue compared with surgical crown lengthening and a shorter overall treatment time compared to orthodontic extrusion ${ }^{10,11}$. Since introduction of the procedure ${ }^{12}$ in 1978 , several case reports and case series have investigated the clinical outcome of crownroot fracture in permanent teeth, thereby validating surgical extrusion as an effective option for treatment of crown-root fractures and sub-gingival caries ${ }^{10,13}$. However, these studies mainly investigated permanent anterior teeth, and those describing clinical results in maxillary premolars have been infrequent.

The adverse effects of surgical extrusion are fracture during extraction, progressive root resorption, increased mobility, marginal bone loss, and tooth loss. Therefore, some dentists are opposed to this procedure ${ }^{10}$. A hybrid technique of orthodontic extrusion before extraction was introduced to prevent extraction failure, increase the periodontal ligament, and prevent external root resorption in cases of intentional replantation $^{14}$.

The aim of the present retrospective case series was to investigate the clinical outcome and prognosis of surgical extrusion after orthodontic extrusion of maxillary premolars.

\section{Materials and Methods}

The present study was conducted after approval from the Institutional Review Board of Seoul National University Bundang Hospital (IRB No. B-1803-459-106).

This was a retrospective case series study that comprised 21 cases from 21 patients who underwent surgical extrusion between 2010 and 2014 at the Department of Periodontology of Seoul National University Bundang Hospital.

The mean age of the patients was $42.1 \pm 14.3$ years, and the age range was 16 to 65 years. There were 7 male and 14 female involved in the study. All patients were in relatively good health with no notable medical history. A physician consultation was indicated in patients who exhibited high blood pressure and were prescribed aspirin daily.

Inclusion criteria were maxillary premolars with a single tapered root and either 1) crown-root fracture with subgingival extension of the fracture line or 2) presence of subgingival caries. All premolar teeth had immobile adjacent teeth or dental implants. Teeth with healthy periodontal tissue especially attached gingiva, physiologic mobility, and normal periodontal pocket depth were examined clinically and radiographically.

Teeth with periodontal disease, pathologic mobility, and divergent or curved roots that could lead to root fracture or damage to the periodontal ligament during extraction were excluded.

In addition, teeth with residual crack line after removal of the fragment and split vertical root fracture were also excluded.

In cases of vital teeth, the root fragment was removed after administration of infiltration anesthesia followed by emergency endodontic treatment, whereas only fragment removal was performed in the same manner in cases of non-vital teeth. Subsequently, the feasibility of surgical extrusion was determined.

\section{Treatment protocol}

An extrusive force of $50 \mathrm{~g}$ was applied for 1 to 2 weeks using a 0.014-inch round NiTi wire (Dentsply Tulsa Dental Specialties, Tulsa, OK, USA) ${ }^{15}$. All patients received 400 mg of ibuprofen orally 30 minutes before surgery. The surgical area was anesthetized with $2 \%$ lidocaine $(1: 100,000$ epinephrine; Huons, Hwaseong, Korea) using an infiltration technique before rinsing the mouth with $0.2 \%$ chlorhexidine gluconate for 1 minute.

Physics forceps (Golden Misch, Detroit, MI, USA) were used to extract the premolar teeth by placing the beaks above the cementoenamel junction. Elevators were not used to prevent damage to the periodontal ligament and marginal bone loss. Conventional forceps were used at the last stage of extraction. Extraction time was recorded in seconds using a stopwatch. The extracted tooth was gently rinsed with cold physiologic saline ${ }^{16}$ and examined under a dental microscope (OPMI Pico; Carl Zeiss, Oberkochen, Germany) to identify vertical cracks or perforations before being repositioned in the socket. Level of insertion was carefully determined based on crown/root ratio, long axis, and location of the subgingival margin. The tooth was rotated by $180^{\circ}$, if required, to achieve a favorable crown-root ratio. Digital pressure was applied to adapt the bucco-lingual bony wall.

Repositioned teeth were splinted using a $0.45 \mathrm{~mm}$ stainless steel wire (Dentaflex; Dentaurum, Ispringen, Germany), and nanofilled flowable composite resin (Filtek Supreme Ultra; 3M ESPE, St. Paul, MN, USA) was cured on the adjacent teeth for 7 to 14 days. Ibuprofen $600 \mathrm{mg}$ was prescribed every 8 hours for 2 days. Root canal treatment was initiated 1 to 2 weeks after extrusion with intra-canal calcium hydroxide dressing for 2 months. Crown fabrication was performed in all cases, and use of post and core was considered where re- 
quired.

Clinical and radiographic evaluations of the extruded teeth were performed during each recall visit at 1, 2, and 3 months after the procedure, followed by recall examinations at 6-month intervals.

\section{Criteria for success and failure}

Two clinicians examined the outcomes independently, and disagreements were resolved by consensus. All cases were categorized as success or failure. Success criteria were presence of a normal periodontal ligament space on radiograph, non-progressive root resorption, absence of periapical radiolucency, normal pocket depth, absence of mobility of the tooth, and absence of marginal bone loss. Non-progressive root resorption or surface root resorption was not considered a failure. Factors other than the success criteria and tooth loss were categorized as failure.

\section{Statistical analyses}

The Fisher's exact test was used to compare variables including tooth type, sex, and effect of $180^{\circ}$ rotation of the tooth. The Mann-Whitney $U$ test was used to evaluate the age of the patient and time needed for extraction. Survival analysis was performed using the log-rank test. Statistical analyses were performed using the PASW Statistics software (ver. 18; IBM Corp., Armonk, NY, USA) at the significance level of 0.05 .

\section{Results}

The mean duration of follow-up was $41.9 \pm 15.2$ months. The longest duration was 77 months for a successful case, and the shortest was 23 months for a case that failed. The extraction time was 2 minutes 57 seconds \pm 3 minutes 7 seconds.

Three cases exhibited increased mobility with a widened periodontal ligament space, which were categorized as failures.(Table 1) No teeth were extracted at the time of the last follow up. The overall success rate was $85.7 \%(n=18)$ with $100 \%$ survival. The log-rank test showed a statistically significant difference for patients older or younger than 54 years $(P=0.025)$.

There was no significant difference among variables of tooth type, age, sex, $180^{\circ}$ rotation, and extraction time.(Table 1) Marginal bone loss and ankylosis were not observed in any
Table 1. Distribution of cases and the prognostic variables affecting the results of surgical extrusion and their contribution

\begin{tabular}{lccc}
\hline \multicolumn{1}{c}{ Variable } & Success $(\mathrm{n}=18)$ & Failure $(\mathrm{n}=3)$ & $P$-value \\
\hline Tooth & & & $0.515^{1}$ \\
$\quad$ First premolar & $6(33.3)$ & $1(33.3)$ & \\
$\quad$ Second premolar & $12(66.7)$ & $2(66.7)$ & \\
Age (yr) & $40(16-65)$ & $46(36-55)$ & $0.960^{2}$ \\
Sex & & & $1.000^{1}$ \\
$\quad$ Female & $12(66.7)$ & $2(66.7)$ & \\
$\quad$ Male & $6(33.3)$ & $1(33.3)$ & \\
$180^{\circ}$ rotation & & & $1.000^{1}$ \\
$\quad$ No & $16(88.9)$ & $3(100)$ & \\
$\quad$ Yes & $2(11.1)$ & $0(0)$ & \\
Extraction seconds & $109(35-846)$ & $101(35-846)$ & $0.339^{2}$ \\
\hline
\end{tabular}

${ }^{1}$ Fisher's exact test. ${ }^{2}$ Mann-Whitney U test.

Values are presented as number (\%) or median (range).

Yong-Hoon Choi et al: Surgical extrusion of a maxillary premolar after orthodontic extrusion: a retrospective study. J Korean Assoc Oral Maxillofac Surg 2019

cases.

\section{Discussion}

Subgingival root caries and secondary caries associated with the prosthesis are common in adult patients. Restoration in such cases is challenging, and placement of the restorative margin at a subgingival level encroaches on the biologic width, resulting in gingival inflammation, periodontal attachment loss, and bone loss. This could lead to gingival bleeding, recession, and periodontal pocket formation ${ }^{17}$. Clinicians should consider the ferrule effect by preserving the coronal and radicular tooth structure to ensure long-term stability of the prosthesis as well as residual root length and shape to maintain a favorable crown-root ratio (maximum 1:1) (,18,19 $^{\text {. It }}$ has been recommended that at least $3 \mathrm{~mm}$ of distance should be maintained from the margin of the crown to the alveolar crest to prevent violation of biologic width. Surgical crown lengthening, orthodontic extrusion, and surgical extrusion were considered as treatment options.

Surgical extrusion is one of the options to obtain the ferrule effect. This procedure involves surgical removal of periodontal tissue to gain the required amount of tooth structure. The disadvantage of this procedure is, assuming no change in the occlusal plane, creation of a less favorable crown-root ratio (increase in the ratio) compared to surgical extrusion, which leads to an increased leverage effect during function ${ }^{20,21}$. Extrusion is a more favorable option to achieve the desirable crown-root ratio but cannot not be practiced in esthetic areas. It is inevitable that removal of sound periodontal tissue could have an adverse effect on adjacent teeth and future dental implants.

Although studies have reported ankylosis as a minor 
event ${ }^{10}$, it is considered an adverse effect of surgical extrusion. Therefore, some clinicians favor orthodontic extrusion ${ }^{22}$. One animal study that histologically examined the results of surgical and orthodontic extrusion reported that both procedures exhibited surface root resorption, which was repaired by new periodontal ligaments to regain normal function of treated teeth ${ }^{23}$. Ankylosis was not observed in either group. The anatomic variation of the root surface may have contributed to a small area of compression during extrusion, which resulted in surface root resorption in the orthodontic extrusion group. This study concluded that both surgical and orthodontic extrusion are favorable for reestablishing the biologic width with the key factor of maintaining the cementum and periodontal ligament on the tooth to prevent root resorption. Orthodontic extrusion before surgical extrusion could contribute to preservation of the periodontal ligament adjacent to the root, which enhances the effectiveness of surgical extrusion as a more conservative treatment option while shortening the duration of treatment. A retrospective study comparing intentional replantation with or without surgical extrusion concluded that the survival rate in the orthodontic extrusion group was significantly higher $(98 \%)$ than that in the nonorthodontic extrusion group $(91 \%)^{15}$. In addition, pre-surgical orthodontic extrusion may increase the height of the marginal bone (Fig. 1) aiding in enhanced stability of the extruded root as well as the future dental implant ${ }^{7}$.

Progressive root resorption is a rare complication of surgical extrusion that was not observed in the present study. A review that evaluated 19 studies on surgical extrusion in humans reported that 8 of 242 teeth demonstrated progressive root resorption ${ }^{10}$. Seven of the teeth that exhibited resorption were surgically extruded using the technique that involved el-

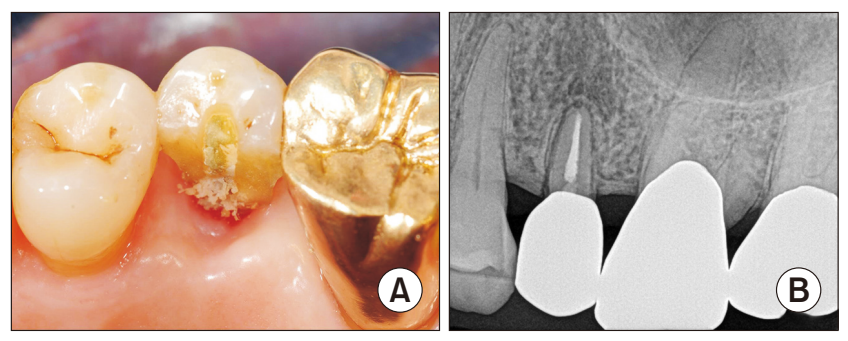

Fig. 1. A. Clinical photograph of maxillary second premolar showing subgingival crown-root fracture resulting in pulp exposure. B. Prominent periodontal ligament space is observed in the 5-year follow-up radiograph. Note the elevated marginal bone level along with root surface, which might be the bone induction capability of periodontal ligament cells attached on to the extruded root surface.

Yong-Hoon Choi et al: Surgical extrusion of a maxillary premolar after orthodontic extrusion: a retrospective study. J Korean Assoc Oral Maxillofac Surg 2019 evation of a flap with exposure of the root apex and extrusive force applied using an elevator ${ }^{13}$. It is advisable to avoid this type of surgical extrusion to reduce progressive root resorption.

The cause of failure was pathologic mobility in the present study ( $\mathrm{n}=3,14.3 \%)$. This was higher than a previous study, which reported a lower rate of mobility $(5 \%)^{10}$. However, the previous study investigated maxillary anterior teeth that experience lower occlusal forces than maxillary premolars ${ }^{24}$. One possible theory is that increased mobility occurs due to an increased crown-root ratio under high occlusal forces. An unsatisfactory crown-root ratio is considered one of the clinical factors that worsens the prognosis of a tooth ${ }^{25}$. However, it is impossible to isolate a single clinical parameter to determine the prognosis of teeth. The crown-root ratio should be evaluated with other parameters such as total alveolar bone support, root configuration, functional occlusal forces, presence of a parafunctional habit, and remaining tooth structure ${ }^{6}$.

Age of the patient above 54 years was the only significant factor among the variables assessed in the present study. Patient age is one of the influencing factors in autotransplantation of teeth ${ }^{26}$. The survival and success rates were significantly lower in patients older than 40 years of age compared to those younger than 40 years of age in cases of autotransplantation to the non-extraction site. The outcomes were attributed to the reduced healing capacity in older patients that prevents attachment loss. Therefore, age of patients should be carefully considered despite good general health.

The comparison between surgical extrusion and an implant-supported single crown is inevitable during the decision making process considering rapid advancement of implants in modern dentistry as the treatment of choice for replacement of missing teeth ${ }^{27}$. The outcome of dental implants has evolved rapidly since its invention in the 1980s. One metaanalysis study reported an overall survival rate of $97 \%$ for implant-supported single crowns ${ }^{28}$.

Although several studies have reported high rates of survival, many surviving implants were categorized as failures (19\%-64\%) depending on applied success criteria ${ }^{29}$. Surgical extrusion is likely to be more cost-effective than a singleimplant-supported restoration ${ }^{30}$. Care must be taken by dental practitioners when selecting the appropriate treatment option based on factors such as age, general health, remaining tooth structure, risk of caries, periodontal prognosis, desire and value of the patient, and economic concerns ${ }^{31,32}$.

The limitation of the present study is the absence of a control group to establish the relationship between interventions 
and outcomes ${ }^{33}$. However, limited clinical studies, and to the best of our knowledge, no randomized controlled trials, have been reported in the literature pertaining to surgical extrusion of maxillary premolars ${ }^{10}$.

\section{Conclusion}

The results of the present study indicated that surgical extrusion of maxillary premolars is a clinically acceptable procedure. Age, sex, and rotation of the tooth by $180^{\circ}$ did not significantly affect clinical outcome. Marginal bone conservation is one positive aspect of this procedure when considering surgical crown lengthening. Marginal bone growth may be expected with this procedure. Therefore, surgical extrusion must be considered by clinicians during treatment planning for extraction and dental implant placement. Future randomized controlled clinical trials between surgical extrusion, orthodontic extrusion, and dental implant must be conducted to compare their outcomes.

\section{ORCID}

Yong-Hoon Choi, https://orcid.org/0000-0001-8222-219X Hyo-Jung Lee, https://orcid.org/0000-0002-0439-7389

\section{Authors' Contributions}

Y.H.C. performed the surgical procedure, collected the data, and wrote the manuscript. H.J.L. participated in data assessment and statistical work. All authors read and approved the final manuscript.

\section{Ethics Approval and Consent to Participate}

The present retrospective study was conducted after approval from the Institutional Review Board of Seoul National University Bundang Hospital (IRB No. B-1803-459-106). All surgical procedures conducted in this study were well-established and clinically proven in previous literature. The practitioner obtained informed consent before surgery. The identity of the patients was not disclosed under any circumstances.

\section{Conflict of Interest}

No potential conflict of interest relevant to this article was reported.

\section{References}

1. Malhotra N, Kundabala M, Acharaya S. A review of root fractures: diagnosis, treatment and prognosis. Dent Update 2011;38:615-6, 619-20, 623-4 passim.

2. Hayes M, Brady P, Burke FM, Allen PF. Failure rates of class V restorations in the management of root caries in adults - a systematic review. Gerodontology 2016;33:299-307.

3. Juloski J, Radovic I, Goracci C, Vulicevic ZR, Ferrari M. Ferrule effect: a literature review. J Endod 2012;38:11-9.

4. Olsburgh S, Jacoby T, Krejci I. Crown fractures in the permanent dentition: pulpal and restorative considerations. Dent Traumatol 2002;18:103-15.

5. Rosenberg ES, Cho SC, Garber DA. Crown lengthening revisited. Compend Contin Educ Dent. 1999;20:527-32, 534, 536-8 passim; quiz 542.

6. Grossmann Y, Sadan A. The prosthodontic concept of crown-toroot ratio: a review of the literature. J Prosthet Dent 2005;93:55962.

7. Alsahhaf A, Att W. Orthodontic extrusion for pre-implant site enhancement: Principles and clinical guidelines. J Prosthodont Res 2016;60:145-55.

8. Faria LP, Almeida MM, Amaral MF, Pellizzer EP, Okamoto R, Mendonça MR. Orthodontic extrusion as treatment option for crown-root fracture: literature review with systematic criteria. J Contemp Dent Pract 2015;16:758-62.

9. Malmgren O, Malmgren B, Frykholm A. Rapid orthodontic extrusion of crown root and cervical root fractured teeth. Endod Dent Traumatol 1991;7:49-54.

10. Elkhadem A, Mickan S, Richards D. Adverse events of surgical extrusion in treatment for crown-root and cervical root fractures: a systematic review of case series/reports. Dent Traumatol 2014;30:1-14.

11. Yuan LT, Duan DM, Tan L, Wang XJ, Wu LA. Treatment for a complicated crown-root fracture with intentional replantation: a case report with a 3.5-year follow up. Dent Traumatol 2013;29:4748.

12. Tegsjõ U, Valerius-Olsson H, Olgart K. Intra-alveolar transplantation of teeth with cervical root fractures. Swed Dent J 1978;2:7382.

13. Tegsjö U, Valerius-Olsson H, Frykholm A, Olgart K. Clinical evaluation of intra-alveolar transplantation of teeth with cervical root fractures. Swed Dent J 1987;11:235-50.

14. Choi YH, Bae JH. Clinical evaluation of a new extraction method for intentional replantation. J Korean Acad Conserv Dent 2011;36:211-8.

15. Choi YH, Bae JH, Kim YK, Kim HY, Kim SK, Cho BH. Clinical outcome of intentional replantation with preoperative orthodontic extrusion: a retrospective study. Int Endod J 2014;47:1168-76.

16. Chen F, Qi S, Lu L, Xu Y. Effect of storage temperature on the viability of human periodontal ligament fibroblasts. Dent Traumatol 2015;31:24-8.

17. Padbury A Jr, Eber R, Wang HL. Interactions between the gingiva and the margin of restorations. J Clin Periodontol 2003;30:379-85.

18. Singh S, Thareja P. Fracture resistance of endodontically treated maxillary central incisors with varying ferrule heights and configurations: in vitro study. J Conserv Dent 2014;17:115-8.

19. Eichelsbacher F, Denner W, Klaiber B, Schlagenhauf U. Periodontal status of teeth with crown-root fractures: results two years after adhesive fragment reattachment. J Clin Periodontol 2009;36:90511.

20. Gegauff AG. Effect of crown lengthening and ferrule placement on static load failure of cemented cast post-cores and crowns. J Prosthet Dent 2000;84:169-79.

21. Meng QF, Chen LJ, Meng J, Chen YM, Smales RJ, Yip KH. Fracture resistance after simulated crown lengthening and forced tooth 
eruption of endodontically-treated teeth restored with a fiber postand-core system. Am J Dent 2009;22:147-50.

22. Chandler KB, Rongey WF. Forced eruption: review and case reports. Gen Dent 2005;53:274-7.

23. Kim SH, Tramontina VA, Ramos CM, Prado AM, Passanezi E, Greghi SL. Experimental surgical and orthodontic extrusion of teeth in dogs. Int J Periodontics Restorative Dent 2009;29:435-43.

24. Koc D, Dogan A, Bek B. Bite force and influential factors on bite force measurements: a literature review. Eur J Dent 2010;4:223-32.

25. McGuire MK, Nunn ME. Prognosis versus actual outcome. III. The effectiveness of clinical parameters in accurately predicting tooth survival. J Periodontol 1996;67:666-74.

26. Tsukiboshi M. Autotransplantation of teeth: requirements for predictable success. Dent Traumatol 2002;18:157-80.

27. Torabinejad M, Anderson P, Bader J, Brown LJ, Chen LH, Goodacre $\mathrm{CJ}$, et al. Outcomes of root canal treatment and restoration, implant-supported single crowns, fixed partial dentures, and extraction without replacement: a systematic review. J Prosthet Dent 2007;98:285-311.

28. Torabinejad M, Dinsbach NA, Turman M, Handysides R, Bahjri K, White SN. Survival of intentionally replanted teeth and implant-supported single crowns: a systematic review. J Endod 2015;41:992-8.

29. Da Silva JD, Kazimiroff J, Papas A, Curro FA, Thompson VP, Vena DA, et al.; Practitioners Engaged in Applied Research and Learning (PEARL) Network Group. Outcomes of implants and restora- tions placed in general dental practices: a retrospective study by the Practitioners Engaged in Applied Research and Learning (PEARL) Network. J Am Dent Assoc 2014;145:704-13.

30. Kim SG, Solomon C. Cost-effectiveness of endodontic molar retreatment compared with fixed partial dentures and single-tooth implant alternatives. J Endod 2011;37:321-5.

31. Torabinejad M, Goodacre CJ. Endodontic or dental implant therapy: the factors affecting treatment planning. J Am Dent Assoc 2006;137:973-7; quiz 1027-8.

32. Iqbal MK, Kim S. A review of factors influencing treatment planning decisions of single-tooth implants versus preserving natural teeth with nonsurgical endodontic therapy. J Endod 2008;34:51929.

33. Brozek JL, Akl EA, Jaeschke R, Lang DM, Bossuyt P, Glasziou P, et al.; GRADE Working Group. Grading quality of evidence and strength of recommendations in clinical practice guidelines: part 2 of 3. The GRADE approach to grading quality of evidence about diagnostic tests and strategies. Allergy 2009;64:1109-16.

How to cite this article: Choi YH, Lee HJ. Surgical extrusion of a maxillary premolar after orthodontic extrusion: a retrospective study. J Korean Assoc Oral Maxillofac Surg 2019;45:254-259. https://doi.org/10.5125/jkaoms.2019.45.5.254 